\title{
Proceeding
}

Supplementary Issue: Winter Conferences of Sports Science. Costa Blanca Sports Science Events, 24 April 2020. Alicante, Spain.

\section{Quality outputs of physical education and sports sciences faculties from the point of view of some labour market institutions}

\author{
MAZEN FARHAN MAJHUL ${ }^{1} \quad$, BAHAA HAIDER FLAYEH ${ }^{1}$, KHALED ASWAD LAIIKH², GHAFFAR SAEED \\ ISSA $^{3}$
}

${ }^{1}$ Faculty of Physical Education and Sports Science, University of Qadisiyah, Iraq

${ }^{2}$ Faculty of Physical Education and Sports Science, Al-Muthanna University, Iraq

${ }^{3}$ College of Physical Education and Sports Science, Wasit University, Iraq

\begin{abstract}
The research problem lies in answering to the following question what is the quality outputs of physical education and sports sciences faculties from the point of view of some labour market institutions and the research goal is to identify the quality outputs of physical education and sports sciences faculties from the point of view of some labour market institutions and the researchers used the descriptive curriculum for the survey style because of its suitability to the research nature problem, the research community was the directors of the directorates of youth and sports and the managers and members of the representatives of the Olympic Committees in the provinces of the Middle Euphrates, where the research community reached (280) official, the research sample consisted of (220) official, it was divided into three groups in a random way, where the first group included a building sample, which reached (100) official, and the second group, which is the sample of the application, consisted of (90) official and the third group, which is the sample of the exploratory experiment consisted of (30) official. To achieve the research objectives and measuring variables, the researchers prepared the research tool by looking at some similar studies and previous related measures It was concluded that the quality outputs from the point of view of the beneficiary was below the desired level, through results analysis the results were not satisfactory about the quality of the qualitative level of graduates and the training programs of the institutions of society as well as consulting.
\end{abstract}

Keywords: Quality outputs; Physical education; Labour market.

Cite this article as:

Majhul, F.M., Flayeh, B.H., Laiikh, K.A., \& Issa, G.S. (2020). Quality outputs of physical education and sports sciences faculties from the point of view of some labour market institutions. Journal of Human Sport and Exercise, 15(2proc), S129-S138. doi:https://doi.org/10.14198//hse.2020.15.Proc2.02

Corresponding author. Faculty of Physical Education and Sports Science, University of Qadisiyah, Iraq.

E-mail: dr.ghafarsaeedissa@gmail.com

Supplementary Issue: Winter Conferences of Sports Science. Costa Blanca Sports Science Events, 24 April 2020. Alicante, Spain.

JOURNAL OF HUMAN SPORT \& EXERCISE ISSN 1988-5202

(c) Faculty of Education. University of Alicante

doi:10.14198/jhse.2020.15.Proc2.02 


\section{INTRODUCTION}

There is no doubt that any system, no matter how large and diverse, it consists of three main components that it cannot be built without them, namely inputs, processes and outputs, and so is the case in education as well, and because our research focuses on the study of outputs, the quality outputs of the educational process can be described as a strategy aimed at employing Information, skills and capabilities to achieve continuous improvement to contribute to the upgrading of the value of community institutions, and quality is thus highlighted through the integrated interaction between the outcomes of the educational process of specializations, experiences and accumulated knowledge and between the mechanisms and processes performed by the organizations And the different sectors according to their orientation and philosophy. It is well known that the outputs of the system are greatly influenced by the quality of their inputs as well as the role of operations within it, so any organization, whatever the nature of its activity, must provide some important elements in its inputs as basic requirements that must be available in order to be converted into outputs in the form of products or services. It is recognized that educational institutions differ from each other in the elements of their systems and all their components according to the visions and messages they adopt and the objectives they seek to achieve, as well as the nature of their specialties and the circumstances of their different environment, and the nature and types of outputs, all of this makes it difficult to achieve the outputs quality for those institutions. So, the educational institutions orientation has become to modernize the educational process system that pays great attention to the targeted outputs. The idea of educational institutions is (interest in the concept of targeted outputs) that they seek to achieve through their efforts to satisfy the needs and requirements of the labour market, and if educational institutions have not achieved the target level of quality assurance in their outputs, they measure and compare their actual outputs to ambitious (targeted) outputs. that guarantees minimum quality standards, which requires that targeted outputs be seen as one of the most important inputs of the modern educational system. The faculties of physical education and sports sciences is considered one of the institutions with diverse outputs to a large extent due to the breadth of the field of work in different sports institutions, and the importance of the current research lies in highlighting the reality of the quality of outputs; Achieving employment opportunities for beneficiaries, and how the quality of education outcomes is suitable to the needs and requirements of the labour market.

\section{Research problem}

The research problem lies in answering to the following question: What is the quality outputs of physical education and sports sciences faculties from the point of view of some labour market institutions.

\section{Research goal}

The research goal is to identify the quality outputs of physical education and sports sciences faculties from the point of view of some labour market institutions.

\section{Research fields}

Human field

Directors and officials of sports institutions (Ministry of Youth and Sports and representatives of the Iraqi National Olympic Committee).

\section{Timeline}

18-1-2019 to 28-2-2019. 
Spatial area

Youth and sports directorates and the headquarters of representatives of the Olympic Committees.

\section{MATERIAL AND METHODS}

\section{Research methodology}

Choosing the appropriate approach to solving a particular problem is one of the most important steps in achieving the goals and the success of the research ${ }^{1}$. and the researchers used the descriptive curriculum for the survey style because of its suitability to the research nature problem.

\section{Participants}

The research community was the directors of the directorates of youth and sports and the managers and members of the representatives of the Olympic Committees in the provinces of the Middle Euphrates, where the research community reached (280) official, the research sample consisted of (220) official, it was divided into three groups in a random way, where the first group included a building sample, which reached (100) official, and the second group, which is the sample of the application, consisted of (90) official and the third group, which is the sample of the exploratory experiment consisted of (30) official.

\section{Measures}

The researchers used the following tools: (Laptop, manual calculator, questionnaire form, data dump form, assistant team, internet, Arabic and foreign sources and references)

\section{Procedures}

Search tool: To achieve the research objectives and measuring variables, the researchers prepared the research tool by looking at some similar studies and previous related measures. Seven fields were prepared as shown in Table 1 they were presented to a group of experts and specialists (Annex 1) to indicate their suitability for the current study and all experts agreed with it (100\%). Each area contained (10) paragraphs, thus amounting to the number of paragraphs of the scale in its initial form ( 40 paragraphs), and the alternatives adopted are (always, often, sometimes, rarely, never), and the grades $(5,4,3,2,1)$ were given.

\section{Analysis}

The researchers used the Statistical Bag of Social Sciences (SPSS) to process the data and it was used in the following topics: (Arithmetic Medium- Pearson Correlation Coefficient - K2 - Standard Deviation Percentage Weight - Weighted Medium - Percentage - Cronbach's alpha Coefficient - T Test for Independent Samples - Spearman-Brown Homogeneity Test).

Table 1. Expert agreement on the study fields.

\begin{tabular}{llr}
\hline S & Field & Percentage \\
\hline 1 & Faculties of physical education, sports science reputation and beneficiary satisfaction & $100 \%$ \\
2 & Conferences, seminars and community-oriented programmes & $100 \%$ \\
3 & Scientific research & $100 \%$ \\
4 & Books and scientific literature aimed at serving the community & $100 \%$ \\
5 & Scientific projects & $100 \%$ \\
6 & Scientific consultancy & $100 \%$ \\
7 & Training programs for community institutions & $100 \%$ \\
\hline
\end{tabular}

${ }_{1}^{1}$ Khattabi,A.(1997). Contemporary Curricula in Physical Education , 1st floor, Amman,Jordon: Dar Al-Fikr. 
Scale phrases preparation

After reviewing the relevant theoretical and similar studies, the phrases were prepared for the scale where each area included (5) phrases and the phrases were presented to a group of experts (Appendix 1) and they agreed to the phrases by $(100 \%)$.

Keys to correct scale statements

Through the interviews mentioned, the researchers adopted the graded "Leckert" method of measurement as a key to correct the phrases, as the calculation of the weights of phrases of (1-5) according to their alternatives and thus the total score of the scale ranged from (35 to 175) degrees and as shown in Table 2.

Table 2. Keys to correct scale statements.

\begin{tabular}{cccccc}
\hline Answer Alternatives & Totally agree & Agree & Neutral & Don't agree & Don't agree totally \\
\hline Weight & 5 & 4 & 3 & 2 & 1 \\
\hline
\end{tabular}

\section{Exploratory experiment}

It is a mini-experiment applied to a small sample of the same research community conducted under similar conditions to the main trial2:

To identify mistakes and obstacles.

To identify the ability of the assistant staff.

To identify the ability of sample members to apply the test.

The scientific basis of the scale

The conditions for the preparation of the scale are of great importance in confirming the safety and scientificity of these preparations and the general conditions of measurement tools are of great importance in the success of the measurement process and the most important of these conditions are the honesty, stability and objectivity of the measurement tool. (Kazem Karim) indicates that the phrase is true if you get a $\mathrm{d}$ coefficient between it and between the dimension and the scale as a whole and vice versa, as the phrase that gets a low correlation coefficient is deleted ${ }^{3}$, and here is an explanation for this:

\section{Scale honesty}

The concept of honesty is one of the most important basic concepts in the field of testing and measurement, the honesty of the test knows that (the extent to which the measurement tool is useful for a particular goal) ${ }^{4}$. Honesty has multiple kinds these kinds are mainly approaches to collect evidence to prove that the scale has Honesty, thus the researchers wanted to verify the scale honesty.

\section{Content honesty}

It is intended to measure the extent of testing for the different aspects or components of the side to be measured 5 . This kind of honesty was achieved when the researchers numbered the scale and identified its fields and phrases with the help of a group of expert professors in the field of sports management, sports psychology, tests and measurement, and was modified in the light of their observations.

\footnotetext{
2 Al-Khafaji,H.A.(2014). The Applied Guide to Writing Psychological and Educational Research, Babil,Iraq.

${ }^{3}$ Al-Jabri,K.K(2011). Research Methods in Education and Psychology, Baghdad,Iraq: Al-Nuaimi Office.

4 Ibrahim,M.A.(1999). Scientific Foundations and Statistical Methods for Examination and Measurement in Physical Education, Amman,Jordon: Dar Al-Fikr.

${ }^{5}$ Rabie,M.S.(1998). Personal Measurement, Cairo,Egypt, 2nd Edition: University Knowledge House.
} 
The hypothetical configuration honesty

As for the honesty of the hypothetical composition and also called the honesty of construction or the honesty of the concept because it depends on the empirical verification of the extent to which the grades of the scale conform to the concepts on which the researchers relied in its construction, the honesty of the construction is one of the most important types of honesty in the stages of the construction of the scale because it constitutes the theoretical framework of the scale and its calculation is more complex than other types of honesty because it is based on theoretical assumptions that are empirically verified ${ }^{6}$.

The researchers verified the authenticity of the hypothetical or constructive configuration in its current scale by the following means:

\section{The two peripheral groups}

Excellence is a psychometric characteristic that indicates the ability of the measurement phrases to distinguish between the examined samples in order to enable the scale to detect individual differences between individuals in the measured characteristic, mainly underlying psychological measurement, because it distinguishes between individuals who got high scores. In the attribute that all phrases measure, than individuals who got lower scores 7 . To achieve this, the researchers adopted the method of the two peripheral groups in calculating the discriminatory power of the standard phrases where the scale contained (35) term sing the statistical bag (SPSS).

\section{Scale Stability}

A fixed test is (a test that gives the results of an approach or the same results if applied more than once in similar circumstances) $)^{8}$ will indicate the stability of the test to the degrees obtained by the individuals themselves at different times of the procedure, meaning that the status of the individual for his group does not change substantially in this case, scale stability means than if the tests of the individual were repeated, their degree would show some stability, and to verify the stability of the scale, the researchers used the following methods:

\section{Split-half method}

In order to find the scale stability factor, the split-half method was adopted because it is not time-consuming and consistent with the test requirements, and the data obtained by the researchers related to the score of (100) is based on the scale as the scale was divided into two parts, the first included term grades which only had odd numbers, and the second part included term grades which only had even numbers. The researchers used the ( $F$ difference test) to confirm the homogeneity of the two halves and the value of calculated $(F)$ is (1.121) which is smaller than its tabular value which equals (1.470) at the degree of freedom (99) and the level of significance was (.05). Simple Pearson correlation coefficient was calculated, but this value represents only the stability factor of half the test, so the value of the stability factor must be corrected in order to have the test as a whole, So the researchers used Spearman-Brown prediction formula to correct the correlation coefficient and thus became the post-correction scale stability was (.885).

\footnotetext{
${ }^{6}$ Al-Khakiani,A.S.(2002). Building a measure of aggression against athletes, codifying it against football players, determining its levels and comparing it according to the playing center. Unpublished doctoral thesis,Baghdad,Iraq: College of Physical Education, University of Baghdad.

${ }^{7}$ Radwan,M.N.(2006). Introduction to Measurement in Physical Physical Education, 1st Edition,Cairo,Egypt: The Book Center for Publishing.

${ }^{8}$ Al-Zyoud,N.F.\& Alayyan,H.A.(2005). Principles, Measurement and Evaluation in Education, 3rd edition,Amman,Jordon: Dar AlFikr.
} 
Cronbach's alpha coefficient

The researchers used the Cronbach's alpha method because it is used in any kind of essay and objectivity questions $^{9}$. In order to calculate the scale stability using Cronbach's alpha coefficient, the researchers relied on a sample of (100) official, and when calculating the value of the stability factor it turned out to be $(.883)$ which is a good and acceptable and reliable stability factor.

Final scale application:

After completing all the requirements and procedures and scale construction, the scale became ready for application and the researchers applied the measure in its final form on the application which consisted of (90) official. Where all questionnaires were retrieved from the sample and were taken for the period of $(1 / 2 / 2 / 2019-28 / 2 / 2 / 2019)$ and after analysing the responses of the research sample, data was collected in a special form.

\section{RESULTS}

Table 3. Results of statistical analysis of the research sample.

\begin{tabular}{ccccccccc}
\hline Variables & $\begin{array}{c}\text { Totally } \\
\text { agree }\end{array}$ & Agree & Neutral & $\begin{array}{c}\text { Don't } \\
\text { agree }\end{array}$ & $\begin{array}{c}\text { Don't } \\
\text { agree } \\
\text { totally }\end{array}$ & $\begin{array}{c}\text { Arithmetic } \\
\text { medium }\end{array}$ & $\begin{array}{c}\text { Standard } \\
\text { deviation }\end{array}$ & $\begin{array}{c}\text { Variation } \\
\text { coefficient }\end{array}$ \\
\hline 1 & 7 & 39 & 23 & 21 & 0 & 2.67 & 1.17 & 41.14 \\
2 & 3 & 37 & 22 & 28 & 0 & 3.58 & 0.79 & 21.68 \\
3 & 2 & 11 & 38 & 39 & 0 & 2.94 & 0.74 & 25.17 \\
4 & 0 & 16 & 34 & 35 & 5 & 2.87 & 0.85 & 29.64 \\
5 & 5 & 15 & 10 & 42 & 10 & 2.59 & 1.16 & 44.92 \\
& & & & & & & & \\
6 & 7 & 13 & 25 & 40 & 5 & 2.77 & 0.79 & 27.85 \\
7 & 6 & 24 & 25 & 35 & 0 & 3.36 & 1.12 & 32.19 \\
8 & 0 & 0 & 31 & 44 & 25 & 2.19 & 0.76 & 34.38 \\
9 & 0 & 7 & 25 & 18 & 40 & 3.23 & 1.29 & 34.81 \\
10 & 5 & 20 & 38 & 27 & 0 & 3.57 & 0.82 & 22.33 \\
& & & & & & & & \\
11 & 5 & 25 & 28 & 18 & 14 & 3.37 & 0.97 & 29.40 \\
12 & 7 & 41 & 26 & 16 & 0 & 3.59 & 0.79 & 22.26 \\
13 & 0 & 37 & 31 & 22 & 0 & 3.26 & 0.77 & 22.41 \\
14 & 0 & 35 & 30 & 25 & 0 & 3.16 & 0.79 & 24.83 \\
15 & 10 & 35 & 21 & 25 & 0 & 3.79 & 0.87 & 21.52 \\
16 & 0 & 20 & 40 & 33 & 2 & 2.78 & 0.80 & 26.51 \\
17 & 10 & 30 & 31 & 19 & 0 & 3.79 & 0.79 & 20.88 \\
18 & 9 & 20 & 51 & 10 & 0 & 3.48 & 0.67 & 17.49 \\
19 & 18 & 25 & 15 & 32 & 0 & 4.26 & 0.75 & 17.41 \\
20 & 0 & 25 & 35 & 30 & 0 & 3.39 & 0.59 & 16.68 \\
& & & & & & & & \\
\end{tabular}

${ }_{9}^{9}$ Al-Aqili,S.A.\& Al-Shayeb,S.M.(1998). Statistical Analysis Using SPSS Programs, Amman, Jordon,1st edition: Dar Al-Shorouk for Publishing and Distribution. 


\begin{tabular}{ccccccccc}
\hline 21 & 0 & 17 & 46 & 20 & 7 & 2.97 & 0.67 & 22.17 \\
22 & 15 & 18 & 32 & 25 & 0 & 3.68 & 0.98 & 27.18 \\
23 & 9 & 18 & 37 & 26 & 0 & 3.20 & 0.86 & 28.38 \\
24 & 0 & 18 & 36 & 25 & 11 & 2.69 & 0.82 & 29.98 \\
25 & 10 & 24 & 22 & 34 & 0 & 3.88 & 0.73 & 18.87 \\
& & & & & & & & \\
26 & 4 & 32 & 24 & 10 & 0 & 3.39 & 0.78 & 23.82 \\
27 & 10 & 32 & 28 & 0 & 0 & 4.27 & 0.61 & 14.70 \\
28 & 0 & 31 & 27 & 12 & 0 & 3.58 & 0.56 & 15.61 \\
29 & 15 & 33 & 22 & 0 & 0 & 4.07 & 0.62 & 15.44 \\
30 & 1 & 21 & 33 & 15 & 0 & 3.21 & 0.75 & 24.17 \\
& & & & & & & & \\
31 & 2 & 20 & 24 & 40 & 4 & 2.54 & 0.91 & 36.30 \\
32 & 12 & 27 & 21 & 30 & 0 & 4.11 & 0.58 & 14.38 \\
33 & 0 & 20 & 45 & 22 & 3 & 2.76 & 0.76 & 27.54 \\
34 & 14 & 26 & 28 & 22 & 0 & 4.08 & 0.67 & 16.55 \\
35 & 0 & 17 & 38 & 27 & 8 & 2.67 & 0.90 & 34.38 \\
\hline
\end{tabular}

\section{DISCUSSION}

\section{The axis of training programs for community institutions}

By noting Table 3 the opinions of the sample agree that the training programs of the institutions of society are at an acceptable level of quality, and this is illustrated by the results of all five phrases (where the mathematical medium of each and the weighted medium is higher than the hypothetical medium and supported by the homogeneity of the answers indicated by the standard deviation This reflects the interest and conviction of labour market institutions in training programs and the way they are designed and produced by colleges. what indicates the lack of conviction of labour market institutions for the quality of colleges in training their staff each according to his specialty. The reasons for not being convinced of the variables of other training programs can be attributed to several reasons, the most important of which is the weakening of the relationship and interaction between colleges and society, from which the College bears a large part of the fact that it is the main exporter of science and knowledge and which has to follow the needs of the labour market. As well as the lack of media and promotional equipments in the faculties of physical education and sports sciences, which leads to the lack of knowledge of the parties in the labour market regarding training programs and their efforts in this field.

\section{The axis of scientific consultations}

The results of the statistical analysis of this axis indicate the lack of conviction of labour market institutions in the advisory information in meeting the needs of society, and the extent to which scientific databases are used to benefit from them, and in fact the colleges bear a large part of this result and therefore because of the weakness of the promotion process and the shortcomings In their services as desired by the institutions of the labour market, and worse is that the faculties of physical education and sports science sought to obtain scientific data and information, but the methods of obtaining them may be restricted by routine procedures that usually embarrass beneficiaries and deprive them of their benefits, as indicated College websites are not being used to their full potential to ensure the dissemination of the most important information. 


\section{The axis of scientific projects}

This is one of the most important topics that have received encouraging and positive results, and this indicates the efforts of universities in their focus on harnessing their scientific projects in the service of the institutions of society although the ambition is higher than the indicated results.

\section{The axis of books and scientific literature aimed at serving the community}

The results of this axis seem relatively acceptable, and it can be said that this is due to the lack of knowledge of labour market institutions about the philosophy and requirements of the scientific approaches determined by specialists and their relevance to practical reality.

\section{The axis of scientific research}

It was found through statistical analysis of the sample that the quality of scientific research is at an acceptable level among the members of the sample, which means that the faculties of physical education and sports sciences does not encouraged their researchers to involve concerned labour market institutions in the completion of research with common objectives, and indicates the weakness of the mechanisms of the colleges in this field which reflects the lack of conviction of labour market institutions in the plan of the faculties of physical education and sports science research and the extent to which they are compatible with the needs and problems of society as well as the extent to which scientific research is made available to beneficiaries outside the colleges.

\section{The axis of conferences and seminars}

This axis is among the research axes which characterized by positive results as the faculties of physical education and sports sciences invite representatives of community institutions to attend and participate in their seminars, conferences and scientific programs, as well as this opinion because it emphasizes that colleges allocate some of their seminars and conferences To increase the awareness and culture of the community because the university cannot implement this unless the institutions of the labour market adopt these recommendations and benefit from the experiences and knowledge of the colleges in their application.

\section{College reputation and the satisfaction of the beneficiary}

Statistical analysis of the sample showed that the focus of the college's reputation and the satisfaction of the beneficiary was at an acceptable level and which is a clear negative indicator on the quality of universities towards the institutions of the labour market in the society because it is completely contrary with to the requirements of the ISO 9001 specification, which is one of its main features is continuous follow-up of customer satisfaction.

\section{CONCLUSIONS}

1. The quality of the results of the faculties of physical education and sports sciences from the point of view of the beneficiary was below the desired level, as it was shown through analysis of the results were not satisfied with the quality of the qualitative level of graduates and the training programs of the institutions of society as well as consulting.

2. It was found through statistical analysis that the labour market institutions were considered negative for the quality of several types of outputs of the faculties of physical education and sports sciences, due to various reasons, some of which fall under the responsibility of colleges and others fall to the institutions of the labour market.

3. It was found through the analysis of the results that the faculties of physical education and sports sciences did not adopt the process of measuring and evaluating the satisfaction of the labour market institutions for 
their performance periodically, and this is a negative indicator towards the quality of their output, because this is contrary to the principle of "continuous follow-up of customer satisfaction".

4. The opinions of the directors and officials of the labour market institutions agree that there is a clear decline in the quality of some outputs for the faculties of physical education and sports sciences, there is also a decrease in the quality of training programs dedicated to the service of the community as well as scientific consultations.

5. The sample agreed on the quality of outputs in each of the research projects, books and scientific literature, scientific research directed to serve the community, conferences and seminars, and the reputation of the College.

6. There is a clear consensus that the university were taking into account the ethical dimensions related to community service, as the results of the study for both categories confirm that the research universities involved representatives of labour market institutions in their seminars, conferences and scientific programs, but those institutions did not invest these Opportunities to support their capabilities and needs.

7. It became clear through research that the institutions of the labour market did not fully invest the outputs of the faculties of physical education and sports sciences, although these outputs were comprehensive, which could cover most of the needs of the business sectors in the labour market.

\section{Recommendations}

1. The need for the faculties of physical education and sports sciences to adapt their outputs to the needs and requirements of the labour market institutions to meet these needs on the one hand, and to ensure that graduates have access to the right jobs for their specialties.

2. The need to give faculties of physical education and sports sciences a great deal of independence and non-interference in their scientific decisions in order to achieve quality in all their outcomes, especially the qualitative level of quality of graduates as one of the most important outcomes of higher education.

3. Giving attention to the principle of continuous improvement in all areas related to the quality of education in order to ensure weaknesses treatment whenever discovered, and to raise the strengths achieved to keep pace with continuous scientific progress.

4. Work on the use of the faculties of physical education and sports sciences for appropriate marketing and promotional strategies to encourage labour market institutions to benefit from their outputs in a broad and effective framework.

5. Periodic and continuous review of the needs of the labour market institutions and study and work to achieve their needs.

6. Develop programs to use targeted outputs and make them one of the most important inputs of the educational process as an early preparation for planned future outputs.

\section{REFERENCES}

Al-Jabri,K.K(2011). Research Methods in Education and Psychology, Baghdad,Iraq: Al-Nuaimi Office. Al-Khafaji,H.A.(2014). The Applied Guide to Writing Psychological and Educational Research, Babil,Iraq. Al-Khakiani,A.S.(2002). Building a measure of aggression against athletes, codifying it against football players, determining its levels and comparing it according to the playing center. Unpublished doctoral thesis,Baghdad,Iraq: College of Physical Education, University of Baghdad.

Al-Aqili,S.A.\& Al-Shayeb,S.M.(1998). Statistical Analysis Using SPSS Programs, Amman, Jordon,1st edition: Dar Al-Shorouk for Publishing and Distribution.

Al-Zyoud,N.F.\& Alayyan,H.A.(2005). Principles, Measurement and Evaluation in Education, 3rd edition,Amman,Jordon: Dar Al-Fikr. 
Ibrahim,M.A.(1999). Scientific Foundations and Statistical Methods for Examination and Measurement in Physical Education, Amman,Jordon: Dar Al-Fikr.

Khattabi,A.(1997). Contemporary Curricula in Physical Education, 1st floor, Amman,Jordon: Dar Al-Fikr. Rabie,M.S.(1998). Personal Measurement, Cairo,Egypt, 2nd Edition: University Knowledge House.

Radwan,M.N.(2006). Introduction to Measurement in Physical Physical Education, 1st Edition,Cairo,Egypt: The Book Center for Publishing. 